\title{
ANATOMIA FOLIAR DE MICROTOMATEIROS FITOCROMO-MUTANTES E ULTRA-ESTRUTURA DE CLOROPLASTOS
}

\author{
Leaf anatomy of micro-tomato phytochrome-mutants and chloroplast ultra-structure
}

\author{
Hyrandir Cabral de Melo ${ }^{1}$, Evaristo Mauro de Castro², Eduardo Alves ${ }^{3}$, Fabiano José Perina ${ }^{3}$
}

\begin{abstract}
RESUMO
Plantas fitocromo-mutantes têm sido utilizadas com o intuito de caracterizar isoladamente, dentre os demais fotorreceptores, a ação dos fitocromos sobre eventos ligados à fotomorfogênese. Raros são os estudos que relatam a ação dos fitocromos sobre aspectos estruturais, embora sejam fundamentais à compreensão do desenvolvimento das plantas. Neste trabalho, objetivou-se analisar características ultraestruturais de cloroplastos e aspectos anatômicos foliares dos microtomateiros (Solanum lycopersicum L. cv. Micro-Tom) fitocromo-mutantes aurea (subexpressa fitocromos), hp1 e atroviolacea (ambos supra-responsivos a eventos mediados por fitocromo) em plantas em estágio de floração. Observou-se que os fitocromos são responsáveis pela expressão de muitas características anatômicas da epiderme foliar, assim como do mesofilo e da ultraestrutura dos cloroplastos.
\end{abstract}

Termos para indexação: Fotomorfogênese, tomateiro.

\section{ABSTRACT}

Phytochrome-mutant plants have been used for phytochrome action characterization among all photoreceptors, in events of photomorphogenesis. Studies relating the phytochrome action on structural aspects, which are fundamental to the comprehension of plant development, are rare. The objective of this work was to analyze chloroplast ultra structure and leaf anatomical characteristics of micro-tomatos (Solanum lycopersicum L. cv. Micro-Tom) phytochrome-mutants aurea (sub express phytochrome), hp1 and atroviolacea (both super express phytochrome events-mediated) in plants in the flowering stage. The results show that phytochromes are responsible for the expression of many characteristics of leaf epidermis, mesophyll and chloroplast ultra-structure.

Index terms: Photomorphogenesis, tomato.

(Recebido em 10 de junho de 2009 e aprovado em 21 de maio de 2010)

\section{INTRODUÇÃO}

O uso de microtomateiro cultivar Micro-Tom (Solanum lycopersicum L.) tem sido proposto como modelo para estudos fisiológicos (Meissner et al., 1997; Pratt et al., 1997) e moleculares (Martí et al., 2006) em função de suas vantagens no padrão morfogenético em relação à Arabidopsis e tomateiros de porte normal.

Tomateiros têm sido utilizados intensivamente em pesquisas na área de fotofisiologia, principalmente utilizando-se plantas mutantes em fotorreceptores. Aspectos morfológicos e genéticos têm sido estudados em microtomateiros (Martí et al., 2006; Meissner et al., 1997) e naqueles fitocromo-mutantes, aspectos relacionados a trocas gasosas, concentração de pigmentos fotossintéticos, nitrogênio e carboidratos (Melo et al., 2009), no entanto, raros são os estudos que envolvem anatomia e ultraestrutura, mesmo em tomateiros fitocromomutantes de porte normal, embora sejam aspectos fundamentais para o entendimento dos processos de desenvolvimento das plantas.
Plantas fitocromo-mutantes possibilitam o estudo da influência dos espectros vermelho (V) e vermelhodistante (VD) da radiação especialmente sobre eventos da fotomorfogênese, que se estendem desde a formação de organelas celulares (Desai \& Hu, 2008) ao florescimento (Smith, 1995; Swada et al., 2008), além de subsidiar o entendimento dos processos que culminam na formação de características que qualificam plantas de sol e sombra (Kim et al., 2005).

Em plantas selvagens, o isolamento entre os diferentes espectros da radiação tem sido dificultado pela complexidade de interação entre os diferentes fotorreceptores (Chen et al., 2004; Schittenhelm et al., 2004). O mutante em fitocromo mais estudado é o aurea, o qual é deficiente na concentração de fitocromo A (phyA), assim como na síntese do cromóforo, o que o torna deficiente em todos os fitocromos (Sharma et al., 1993). Os mutantes high pigment 1 (hp1) e atroviolacea (atv) apresentam mutação na via de transdução de sinais, expressando hipersensibilidade de respostas

1Universidade Federal de Goiás/UFG - Instituto de Ciências Biológicas/ICB - 74001-970 - Goiânia, GO - hyrandir@yahoo.com.br

2Universidade Federal de Lavras/UFLA - Departamento de Biologia/DBI - Lavras, MG

${ }^{3}$ Universidade Federal de Lavras/UFLA - Departamento de Fitopatologia/DFP - Lavras, MG 
em processos mediados por fitocromo (Peters et al., 1998).

A concentração de pigmentos tem sido a característica de plantas fitocromo-mutantes mais estudada. Os conteúdos de clorofila e antocianina são reduzidos nos mutantes aurea, em comparação às plantas selvagens, durante todo o ciclo de vida das plantas, mas, principalmente, em estágio inicial de crescimento (Terry \& Kendrick, 1999), enquanto que nos mutantes hp1 e atv o conteúdo desses pigmentos, além dos carotenóides, são maiores em relação às plantas selvagens (Kerckhoffs et al., 1997).

Objetivou-se, neste trabalho, caracterizar aspectos ultraestruturais de cloroplastos e aspectos anatômicos foliares de microtomateiros, cultivar Micro-Tom, fitocromomutantes.

\section{MATERIAL E MÉTODOS}

Trinta mudas, escolhidas de acordo à similaridade em porte e vigor, dos mutantes aurea, hp1 e atroviolacea e da cultivar Micro-Tom (MT) foram cultivadas em vasos plásticos de capacidade de $150 \mathrm{~mL}$ contendo substrato Plantmax ${ }^{\circledR}$ e vermiculita $(1: 1)$ e $0,5 \mathrm{~g}$ de NPK, na formulação 4-14-8, distribuído na borda de cada vaso. As plantas foram acondicionadas em câmaras de crescimento iluminadas com lâmpadas fluorescentes brancas, recebendo radiação média de $150 \mu \mathrm{mol} \mathrm{m}^{-2} \mathrm{~s}^{-1}$, na altura central da copa das plantas adultas, e submetidas a um fotoperíodo de 16 horas, durante o período diurno (no qual a temperatura é mais elevada). A irrigação foi realizada diariamente, duas vezes ao dia, mantendo a umidade do substrato próximo à capacidade de campo. No interior das câmaras de crescimento a temperatura máxima diária foi de $32^{\circ} \mathrm{C}$ e mínima noturna de $18^{\circ} \mathrm{C}$, medida na altura central da copa das plantas adultas, sendo a temperatura média de $26^{\circ} \mathrm{C}$.

Uma vez por semana, durante o cultivo das plantas, foi realizada adubação foliar com uma solução diluída 10 vezes a partir da solução estoque, a qual continha em $1 \mathrm{~L} 7 \mathrm{~g}$ do composto nutricional de Peters ${ }^{\circledR} 20-20-20+20 \mathrm{~g}$ de $\mathrm{Ca}\left(\mathrm{NO}_{3}\right)_{2}+5 \mathrm{~g}$ de $\mathrm{MgSO}_{4}+3 \mathrm{~g} \mathrm{~K}_{2} \mathrm{SO}_{4}$.

No $30^{\circ}$ dia de cultivo, período no qual as plantas se encontravam em estágio de floração, foram coletados folíolos da região mediana da terceira folha completamente expandida, do ápice para a base da planta. Para análises anatômicas dos folíolos, estes foram fixados em FAA 70\% (formaldeído + ácido acético + álcool etílico 70\%) (Kraus \& Arduim, 1997), durante 72 horas e, posteriormente, conservados em álcool $70 \%$ até o momento da realização das análises.
Utilizou-se micrótomo de mesa para a obtenção de seções transversais do terço médio foliar. Seções paradérmicas foram obtidas manualmente no terço médio dos folíolos. Os dados de densidade estomática, densidade de células da epiderme, número de tricomas e índice estomático foram obtidos de seis plantas de cada tipo de microtomateiro estudado e cada folha analisada em quatro campos. A contagem das células foi realizada com câmara clara e a densidade estomática foi determinada de acordo com metodologia de Labouriau et al. (1961). O índice estomático $(\mathrm{Si})$ foi calculado segundo a fórmula: $\mathrm{Si}(\%)=$ $(\mathrm{Sn} /(\mathrm{Sn}+\mathrm{Em})) \times 100$, sendo $\mathrm{Sn}$ o número de estômatos e Em o número de células da epiderme (Cutter, 1986).

Os dados de espessura dos tecidos da lâmina foliar também foram obtidos de seis plantas de cada microtomateiro estudado e observados em três campos por folha. As determinações de espessura de tecidos e células foram realizadas utilizando-se uma ocular micrométrica acoplada em microscópio de luz Olympus BX-60.

Dez células do parênquima paliçádico (o qual era constituído por uma única camada), escolhidas aleatoriamente, e dez células do parênquima lacunoso, também escolhidas aleatoriamente na camada adjacente à epiderme abaxial, foram selecionadas, em três plantas para cada tipo de microtomateiro estudado, para realização da contagem do número de cloroplastos por célula, do comprimento e largura dos cloroplastos, área dos cloroplastos, contagem do número de grãos de amido por cloroplasto e para determinação da área total dos grãos de amido por cloroplasto. A preparação das amostras para o processo de ultramicrotomia e análise por meio de microscopia de transmissão foram realizadas segundo Alves (2004).

$\mathrm{O}$ experimento foi conduzido em delineamento inteiramente casualizado. Após análise de variância dos dados obtidos, utilizou-se o teste de Tukey, a 5\% de probabilidade de erro, para agrupamento das médias em classes distintas.

\section{RESULTADOS E DISCUSSÃO}

\section{Características anatômicas}

O mutante hp1 foi o que apresentou maior densidade estomática na epiderme da face adaxial, enquanto que todos os mutantes em fitocromo apresentaram densidade estomática superior à cultivar Micro-Tom (MT) na epiderme da face abaxial. Os mutantes aurea e hp1 revelaram os maiores diâmetros equatorial e polar dos estômatos na epiderme adaxial. Na face abaxial, 
apenas o mutante aurea destacou-se pelas maiores dimensões dos diâmetros polar e equatorial de seus estômatos (Tabela 1). O comportamento estomático observado para o mutante hp1 é similar àquele ocorrido em plantas expostas a altas intensidades de radiação em relação àquelas expostas à baixa intensidade (Nascimento et al., 2005; Lima Junior et al., 2006).

Diferentemente do mutante hp1, o mutante atv expressou o menor tamanho dos estômatos e densidade estomática na epiderme adaxial (Tabela 1), evidenciando assim diferenças de respostas estruturais entre esses mutantes às condições do experimento, embora ambos sejam considerados super-responsivos a eventos mediados por fitocromos. A intensidade da radiação é um fator determinante nessa variação de respostas. A mutação do atv torna a planta mais sensível e supra-responsiva à altas intensidades de radiação para o desencadeamento de respostas fisiológicas inerentes à sua mutação, à exemplo da produção de antocianina, diferentemente do mutante hp1, o qual se torna supra-responsivo à radiação tanto em baixa quanto em alta fluência (Huub et al., 1997; Kerckhoffs et al., 1997).

A maior densidade de células epidérmicas ocorrentes na face adaxial foi observada no mutante aurea, enquanto que as menores densidades ocorreram nos mutantes hp1 e atv, no entanto, estes expressaram os maiores índices estomáticos nessa mesma face epidérmica e o mutante atv o maior índice também na epiderme da face abaxial (Tabela 1). Aumento nos índices estomáticos é também um evento comum à folhas de sol, se comparadas às de sombra (Nascimento et al., 2005; Lima Junior et al., 2006), e, geralmente, está associado a uma diminuição no tamanho dos estômatos, o que vem a garantir o suprimento de $\mathrm{CO}_{2}$ necessário à fotossíntese sem que haja perda excessiva de água por meio da transpiração. Isso é possível, em razão da diminuição do póro estomático causar maior resistência à saída de água do que a entrada de $\mathrm{CO}_{2}$ pelo estômato (Bidwell, 1964). Embora tenha havido aumento nos índices estomáticos nos mutantes que superexpressam eventos desencadeados por fitocromo, hp1 e atv, somente o mutante atv apresentou tamanho reduzido dos estômatos, quanto ao diâmetro equatorial, na epiderme adaxial, se comparado à cultivar MT. No entanto, ambos os diâmetros polar e equatorial das duas faces epidérmicas do mutante atv e na face abaxial do mutante hp1 foram menores que aqueles encontrados para o mutante aurea, o qual suexpressa eventos desencadeados pelos fitocromos.

A densidade de tricomas não glandulares na epiderme da face adaxial foi menor nos mutantes que superexpressam fitocromo (Tabela 1). A função dos tricomas não glandulares depende do órgão onde se encontram, de sua densidade e até mesmo do ângulo de inclinação. A alta densidade em folhas pode atuar como uma barreira

Tabela 1 - Características anatômicas da epiderme foliar de micro-tomateiros em estádio de floração, cultivar MicroTom e seus respectivos mutantes em fitocromo.

\begin{tabular}{lcccc}
\hline & \multicolumn{4}{c}{ Micro-tomateiros } \\
\cline { 2 - 5 } Características avaliadas & Micro-Tom & aurea & $\mathrm{hp} 1$ & atroviolacea \\
\hline Dens. Est. Ep. Adaxial $\left(\mathrm{n}^{\circ} / \mathrm{mm}^{2}\right)$ & $74.61 \mathrm{ab}$ & $65.36 \mathrm{bc}$ & $78.31 \mathrm{a}$ & $59.20 \mathrm{c}$ \\
Dens. Est. Ep. Abaxial $\left(\mathrm{n}^{\circ} / \mathrm{mm}^{2}\right)$ & $160.31 \mathrm{~b}$ & $217.68 \mathrm{a}$ & $210.24 \mathrm{a}$ & $194.86 \mathrm{a}$ \\
Dens. Cel. Ep. Adaxial $\left(\mathrm{n}^{\circ} / \mathrm{mm}^{2}\right)$ & $754.16 \mathrm{~b}$ & $891.08 \mathrm{a}$ & $622.30 \mathrm{c}$ & $465.58 \mathrm{~d}$ \\
Dens. Cel. Ep. Abaxial $\left(\mathrm{n}^{\circ} / \mathrm{mm}^{2}\right)$ & $749.84 \mathrm{a}$ & $774.51 \mathrm{a}$ & $779.46 \mathrm{a}$ & $571.01 \mathrm{~b}$ \\
Índice Estomático Ep. Adaxial & $9.10 \mathrm{~b}$ & $6.87 \mathrm{c}$ & $11.14 \mathrm{a}$ & $11.14 \mathrm{a}$ \\
Índice Estomático Ep. Abaxial & $17.80 \mathrm{c}$ & $22.25 \mathrm{~b}$ & $21.10 \mathrm{~b}$ & $25.68 \mathrm{a}$ \\
Diâm. Polar Est. Ep Adaxial $(\mu \mathrm{m})$ & $26.71 \mathrm{~b}$ & $28.69 \mathrm{a}$ & $29.25 \mathrm{a}$ & $26.11 \mathrm{~b}$ \\
Diâm. Eq. Est. Ep Adaxial $(\mu \mathrm{m})$ & $19.03 \mathrm{~b}$ & $20.71 \mathrm{a}$ & $20.60 \mathrm{a}$ & $17.83 \mathrm{c}$ \\
Diâm. Polar Est. Ep Abaxial $(\mu \mathrm{m})$ & $23.70 \mathrm{~b}$ & $26.58 \mathrm{a}$ & $24.18 \mathrm{~b}$ & $24.07 \mathrm{~b}$ \\
Diâm. Eq. Est. Ep. Abaxial $(\mu \mathrm{m})$ & $17.26 \mathrm{~b}$ & $18.94 \mathrm{a}$ & $17.36 \mathrm{~b}$ & $17.02 \mathrm{~b}$ \\
Dens. Tric. Ep. Adaxial $\left(\mathrm{n}^{2} / \mathrm{mm}^{2}\right)$ & $32,25 \mathrm{a}$ & $31,00 \mathrm{a}$ & $20,91 \mathrm{~b}$ & $19,50 \mathrm{~b}$ \\
Dens. Tric. Ep. Abaxial $\left(\mathrm{n}^{2} / \mathrm{mm}^{2}\right)$ & $46,50 \mathrm{a}$ & $51,04 \mathrm{a}$ & $40,37 \mathrm{a}$ & $40,25 \mathrm{a}$ \\
\hline
\end{tabular}

Dens. Est. Ep.: Densidade estomática da epiderme; Dens. Cel. Ep.: Densidade de células da epiderme; Ep.: epiderme; Diâm. Polar Est. Ep: Diâmetro polar dos estômatos da epiderme; Diâm. Eq. Est. Ep: Diâmetro equatorial dos estômatos da epiderme; Dens. Tric.: Densidade de tricomas não glandulares. Médias seguidas de mesma letra, entre micro-tomateiros, não diferem entre si pelo teste de Tukey $(P \leq 0.05)$. 
mecânica à insolação direta nas células ordinárias da epiderme, contribuindo à redução de temperaturas altas e a perda excessiva de água (Werker, 2000). No entanto, a alta densidade de tricomas pode ampliar a superfície de transpiração (Jonhson, 1975). É possível que a baixa intensidade de radiação e a temperatura controlada das condições do experimento deste trabalho tenham contribuído para uma menor densidade de tricomas na epiderme da face adaxial nos mutantes hp1 e atv em relação aos demais microtomateiros, porém há de se considerar um efeito de suas mutações, uma vez que todos estavam submetidos às mesmas condições ambientais.

A espessura da epiderme em plantas é uma característica altamente plástica e tem se mostrado responsiva a diferentes situações ambientais às quais as plantas são submetidas. Neste trabalho observou-se que os mutantes hpl e atv apresentaram maior espessura da epiderme da face adaxial, se comparados à cultivar MT (Tabela 2). Esse comportamento ocorre com frequência em folhas de sol, se comparadas às de sombra (Nakazono et al., 2001; Nascimento et al., 2005; Castro et al., 2005; Lima Junior et al., 2006), e a ocorrência, neste trabalho, nos mutantes que superexpressam fitocromo, diferentemente dos demais micro-tomateiros, indica uma participação efetiva dos fitocromos nessa diferenciação. Na epiderme da face abaxial, somente o mutante atv obteve maior espessura se comparada aos demais microtomateiros (Tabela 2).

O mutante hp1 também expressou a maior espessura do parênquima paliçádico e lacunoso em relação a todos os demais microtomateiros (Tabela 2), o que também é uma característica marcante de folhas de sol, quando comparadas às folhas de sombra (Hoflacher \& Bauer, 1982; Terashima et al., 2001). Esses parênquimas apresentam grande capacidade de respostas aos estímulos de radiação luminosa, influenciando a espessura do limbo foliar. O aumento na espessura ocorre em função de modificações no padrão de expansão de células do mesofilo, alongando- se, ou pelo aumento no número de camada de células do parênquima paliçádico (Terashima et al., 2001; Kim et al., 2005), contribuindo, assim, para o direcionamento e absorção mais uniforme da radiação pelos tecidos do mesofilo. Não foram observadas variações no número de camadas de células entre os diferentes tratamentos estudados neste trabalho, indicando que o aumento na espessura dos parênquimas ocorreu em função do processo de alongamento celular.

A espessura do parênquima paliçádico encontrado no mutante atv foi similar à cultivar MT e o parênquima lacunoso menos espesso que o desta cultivar (Tabela 2), reafirmando, assim, a diferença no padrão de resposta estrutural entre os dois mutantes que superexpressam fitocromo, hpl e atv, provavelmente influenciado pelo requerimento diferenciado de fluxo de radiação para o desencadeamento de respostas que caracterizam suas mutações (Huub et al., 1997; Kerckhoffs et al., 1997).

Para a espessura dos parênquimas paliçádico e lacunoso, o mutante aurea obteve os menores valores para esse parâmetro (Tabela 2), e, portanto, confirma a participação dos fitocromos sobre a espessura dos tecidos do mesofilo, visto que, este mutante tem deficiência no conteúdo desses fotorreceptores. A diminuição da espessura dos tecidos do mesofilo é também uma resposta comum às condições de baixo fluxo de radiação (Hoflacher \& Bauer, 1982; Terashima et al., 2001).

Estudos de fotomorfogênese relacionados à especificidade de fotorreceptores tem sido dificultado pela forte interação entre os diferentes receptores existentes. Já são bastante conhecidas as interações ente os fotorreceptores dos espectros do azul/UV-A, as fototropinas e criptocromos, e da radiação $\mathrm{V}$ e $\mathrm{VD}$, os fitocromos, além de já se ter sido comprovada a interação desses fotorreceptores com outros ainda não caracterizados, como aqueles para o espectro do UV-B (Briggs \& Olney, 2001; Chen et al., 2004).

Tabela 2 - Espessura de tecidos do limbo foliar de micro-tomateiros em estádio de floração, cultivar Micro-Tom e seus respectivos mutantes em fitocromo.

\begin{tabular}{lcccc}
\hline \multirow{2}{*}{ Micro-tomateiros } & \multicolumn{4}{c}{ Espessura de tecidos $(\mu \mathrm{m})$} \\
\cline { 2 - 5 } & $\begin{array}{c}\text { Epiderme adaxial } \\
(\mu \mathrm{m})\end{array}$ & $\begin{array}{c}\text { Parênquima } \\
\text { paliçádico }(\mu \mathrm{m})\end{array}$ & $\begin{array}{c}\text { Parênquima } \\
\text { lacunoso }(\mu \mathrm{m})\end{array}$ & $\begin{array}{c}\text { Epiderme } \\
\text { abaxial }(\mu \mathrm{m})\end{array}$ \\
\hline Micro-Tom & $22.70 \mathrm{~b}$ & $90.61 \mathrm{~b}$ & $105.00 \mathrm{~b}$ & $17.85 \mathrm{~b}$ \\
aurea & $22.25 \mathrm{~b}$ & $67.22 \mathrm{c}$ & $91.87 \mathrm{c}$ & $17.37 \mathrm{~b}$ \\
hp1 & $27.30 \mathrm{a}$ & $110.12 \mathrm{a}$ & $118.50 \mathrm{a}$ & $17.82 \mathrm{~b}$ \\
atroviolacea & $27.22 \mathrm{a}$ & $96.27 \mathrm{~b}$ & $92.37 \mathrm{c}$ & $20.00 \mathrm{a}$ \\
\hline
\end{tabular}

Médias seguidas de mesma letra, entre micro-tomateiros, não diferem entre si pelo teste de Tukey $(P \leq 0.05)$. 
Raras são as pesquisas que relatam o efeito direto da ação de fitocromos sobre a morfologia foliar. No entanto, Kozuka et al. (2005) relatam que o controle da fotomorfogênese foliar em resposta à radiação V/VD é predominantemente determinado pelo fitocromo B (phyB). Portanto, espera-se que mutações fotomorfogênicas que alterem a síntese de phyB ou sua via de transdução de sinais, à exemplo dos mutantes utilizados neste trabalho, causem alterações morfológicas nas folhas.

Embora não tenham sido usados mutantes isolados para tipos específicos de fitocromo neste trabalho, podese considerar o mutante aurea como deficiente em phyB, para fins de comparação, uma vez que sua mutação o torna deficiente na síntese de cromóforo, tornando-o, portanto, deficiente em todos os tipos de fitocromo, visto que, o cromóforo é comum a todos eles (Terry \& Kendrick, 1996). No mesmo sentido pode-se considerar os mutantes atv e hp1 super-responsivos para eventos desencadeados pelo phyB, uma vez que suas mutações não são isoladas para tipos específicos de fitocromos (Kendrick et al., 1997).

Em concordância com a influência dos fitocromos sobre o comportamento estomático encontrado para o mutante hp1 neste trabalho (Tabela 1), Dara-5, um tomateiro mutante que superexpressa phyB, apresentou aumento de $28 \%$ na densidade estomática em relação ao selvagem (Schittenhelm et al., 2004).

Apesar de Nagatani et al. (1993) não terem encontrado efeito do phyA sobre mudanças na morfologia foliar de Arabidopsis thaliana (L.) Heynh., Smith (1995) propõe que phyA e phyB podem, predominantemente, controlar o alongamento polar de células se comparados aos demais tipos de fitocromos, os quais podem ser responsáveis pelo alongamento não-direcional das células. Tsukaya et al. (2002) sugerem que a mutação em phyB afeta não somente o alongamento celular, mas também o número de células na lâmina foliar. Esses autores, trabalhando com folhas de Arabidopsis thaliana mutante em phyB, consideraram esta mutação responsável pela diminuição no tamanho e número de células dos tecidos do mesofilo, resultando em folhas menos espessas que aquelas das plantas selvagens. Resultado compatível foi observado neste trabalho para o mutante aurea, o qual obteve uma redução de $26 \%$ na espessura do parênquima paliçádico e $12,5 \%$ na espessura do parênquima lacunoso em relação a cultivar MT (Tabela 2). Considerando-se a análise em secção transversal foliar, essa redução pode ser atribuída a mudanças no comprimento das células, visto que não foram detectadas diferenças no número de camadas dos parênquimas que compõem o mesofilo.

\section{Características ultra-estruturais}

O comprimento dos cloroplastos observados no parênquima paliçádico das plantas mutantes hp1 foi maior que aqueles dos demais microtomateiros, enquanto que a largura diminuiu em todos os cloroplastos dos microtomateiros fitocromo-mutantes no parênquima lacunoso, quando comparados à cultivar MT (Tabela 3).

No parênquima lacunoso dos mutantes hp1 e atv, houve uma diminuição na área individual dos cloroplastos em relação à cultivar MT e ao mutante aurea, mas concomitantemente, houve um aumento no número de cloroplastos por célula (Tabela 3).

Além da visível diferença em número e área de cloroplasto por célula entre os parênquimas paliçádico e lacunoso (Tabela 3) Terashima et al. (1986) observaram que os cloroplastos presentes no parênquima paliçádico apresentam características de cloroplastos de sol, com menor número de tilacóides por granum, enquanto que na mesma folha, aqueles presentes no parênquima lacunoso já apresentam características de cloroplastos de sombra, com granum mais espesso e com maior número de tilacóides por granum.

Kasperbauer \& Hamilton (1984) observaram que o comprimento dos cloroplastos de tabaco, após a exposição da planta à radiação VD era maior que o comprimento dos cloroplastos nas plantas expostas à radiação no espectro do V, sendo o oposto observado para a largura. Esses autores também relatam que o número de cloroplastos é reduzido após a exposição das plantas à radiação VD. O presente trabalho corrobora com a pesquisa supracitada no sentido de que o tamanho e, principalmente, o número dos cloroplastos são efetivamente influenciados pela atividade dos fitocromos (Tabela 3), os quais são os fotorreceptores responsáveis pela absorção de ambas as radiações V e VD.

Assim como se observou aumento no número de cloroplastos no mutante $\mathrm{hp} 1$ em relação à cultivar MT nesse trabalho (Tabela 3), Liu et al. (2004) também observaram um aumento de $30 \%$ no número de cloroplastos do mutante de tomateiro hp1 em relação ao selvagem. No entanto, a maior expressão no aumento do número de cloroplastos por célula em relação ao selvagem, neste trabalho, ocorreu para a o mutante atv, tendo atingindo um aumento de mais de $50 \%$ no número de cloroplastos por célula, no parênquima paliçádico, em relação a cultivar MT (Tabela 3). Sugere-se que esse maior número de cloroplastos por célula dos mutantes hp1 e atv, observados neste trabalho, em relação aos demais microtomateiros, contribuam para o aumento no conteúdo de pigmentos fotossintetizantes comumente ocorrentes nesses mutantes (Kerckhoffs et al., 1997). 
Tabela 3 - Características dos cloroplastos de micro-tomateiros, em estádio de floração, cultivar Micro-Tom e seus respectivos mutantes em fitocromo.

\begin{tabular}{|c|c|c|c|c|}
\hline \multirow{2}{*}{ Características avaliadas } & \multicolumn{4}{|c|}{ Micro-tomateiros } \\
\hline & Micro-Tom & aurea & hp1 & atroviolacea \\
\hline \multicolumn{5}{|c|}{ Parênquima Paliçádico } \\
\hline Comprimento cloroplastos $(\mu \mathrm{m})$ & $5,71 b$ & $6,52 \mathrm{ab}$ & $7,53 \mathrm{a}$ & $5,83 \mathrm{~b}$ \\
\hline Largura cloroplastos $(\mu \mathrm{m})$ & $2,36 \mathrm{a}$ & $3,68 \mathrm{a}$ & $2,64 \mathrm{a}$ & $2,39 \mathrm{a}$ \\
\hline Área cloroplastos $\left(\mu \mathrm{m}^{2}\right)$ & $10,63 \mathrm{a}$ & $14,08 \mathrm{a}$ & $14,00 \mathrm{a}$ & $10,68 \mathrm{a}$ \\
\hline $\mathrm{N}^{\mathrm{o}}$ cloroplasto/célula & $17,6 \mathrm{c}$ & $22,10 \mathrm{~b}$ & $18,50 \mathrm{bc}$ & $26,60 \mathrm{a}$ \\
\hline Área amido/cloroplasto $\left(\mu \mathrm{m}^{2}\right)$ & $1,06 \mathrm{~b}$ & $0,7 \mathrm{~b}$ & $4,87 \mathrm{a}$ & $4,06 \mathrm{a}$ \\
\hline $\mathrm{N}^{\circ}$ amido/cloroplasto & $1,8 \mathrm{a}$ & $1,7 \mathrm{a}$ & $1,6 \mathrm{a}$ & $1,4 \mathrm{a}$ \\
\hline \multicolumn{5}{|c|}{ Parênquima lacunoso } \\
\hline Comprimento cloroplastos $(\mu \mathrm{m})$ & $5,04 \mathrm{a}$ & $5,57 \mathrm{a}$ & $5,53 \mathrm{a}$ & $5,56 \mathrm{a}$ \\
\hline Largura cloroplastos $(\mu \mathrm{m})$ & $3,47 \mathrm{a}$ & $2,45 \mathrm{~b}$ & $2,17 \mathrm{~b}$ & $2,10 \mathrm{~b}$ \\
\hline Área cloroplastos $\left(\mu \mathrm{m}^{2}\right)$ & $13,8 \mathrm{a}$ & $10,73 \mathrm{ab}$ & $8,56 \mathrm{~b}$ & $8,54 \mathrm{~b}$ \\
\hline $\mathrm{N}^{\mathrm{o}}$ cloroplasto/célula & $6,3 \mathrm{bc}$ & $5,3 \mathrm{c}$ & $8,4 \mathrm{a}$ & $7,3 \mathrm{ab}$ \\
\hline Área amido/cloroplasto $\left(\mu \mathrm{m}^{2}\right)$ & $1,58 \mathrm{ab}$ & $0,76 \mathrm{~b}$ & $1,8 \mathrm{a}$ & $2,40 \mathrm{a}$ \\
\hline $\mathrm{N}^{\mathrm{o}}$ amido/cloroplasto & $1,8 \mathrm{a}$ & $0,9 \mathrm{a}$ & $1,4 \mathrm{a}$ & $1,3 \mathrm{a}$ \\
\hline
\end{tabular}

Médias seguidas de mesma letra, entre microtomateiros, não diferem entre si pelo teste de Tukey $(P \leq 0.05)$.

O mutante aurea expressou a menor área total de amido por cloroplasto dentre os demais microtomateiros, tanto no parênquima paliçádico quanto no lacunoso (Tabela 3), enquanto os mutantes hp1 e atv expressaram as maiores áreas (Tabela 3). Assim como observado para os cloroplastos, Kasperbauer \& Hamilton (1984) já haviam observado, pelas submissões de plantas de fumo à radiação V e VD, que o tamanho dos grãos de amido é influenciado pelos fitocromos. Os resultados encontrados neste trabalho sugerem uma influência direta do conteúdo de pigmentos fotossintéticos nos mutantes estudados (Sharma et al., 1993; Kerckhoffs et al., 1997) sobre este parâmetro analisado, uma vez que é de amplo conhecimento que o amido é um produto da atividade fotossintética.

\section{CONCLUSÕES}

Os espectros V e VD da radiação global provocam mudanças estruturais e ultra-estruturais foliares que podem determinar a formação de características típicas de folhas de sol e sombra.

Tamanho e número de cloroplastos por célula, assim como o tamanho dos grãos de amido sofrem influência de sinalização dependente de fitocromos.

Mudanças estruturais e ultraestruturais foliares decorrem de diferenças no padrão de sinalização inerentes aos mutantes hp1 e atv, mesmo ambos apresentando hipersensibilidade de respostas à radiação V e VD.

\section{AGRADECIMENTOS}

Aos professores Lázaro E. Perez e Rogério F. Carvalho pela concessão do material vegetal.

\section{REFERÊNCIAS BIBLIOGRÁFICAS}

ALVES, E. Introdução à microscopia eletrônica de varredura. Lavras: UFLA/FAEPE, 2004. 43p.

BIDWELL, R.G.S. Protein synthesis and turn over in cultured plant tissue: source of carbon and fate of protein breakdown products. Nature, London, v.203, p.367-373, 1964.

BRIGGS, W.; OLNEY, M.A. Photoreceptors in plant photomorphogenesis to date: five phytochromes, two cryptochromes, one phototropin, and one superchrome. Plant Physiology, Washington, v.125, p.85-88, 2001.

CASTRO, E.M.; PINTO, J.E.B.P.; MELO, H.C.; SOARES, Â.M.; ALVARENGA, A.A.; LIMA JÚNIOR, É.C.

Aspectos anatômicos e fisiológicos de plantas de guaco submetidas a diferentes fotoperíodos. Horticultura Brasileira, Brasília, v.23, p.846-850, 2005.

CHEN, M.; CHORY, J.; FANKHAUSER, C. Light signal transduction in higher plants. Annual Review Genetics, v.38, p.87-117, 2004. 
CUTTER, E.G. Anatomia vegetal: parte I, células e tecidos. 2.ed. São Paulo: Roca, 1986. 304p.

DESAI, M.; HU, J. Light induces peroxisome proliferation in Arabidopsis seedlings through the photoreceptor phytochrome A, the transcription Factor HY5 HOMOLOG, and the peroxisomal protein PEROXIN. Plant Physiology, Washington, v.146, p.1117-1127, 2008.

HOFLACHER, H.; BAUER, H. Light acclimation in leaves of the juvenile and adult life phases of ivy (Hedera helix). Physiologia Plantarum, Copenhagen, v.56, p.177-182, 1982.

HUUB, L.; KERCKHOFFS, J.; KENDRICK, R.E. Photocontrol of anthocyanin biosynthesis in tomato. Journal of Plant Research, v.110, p.141-149, 1997.

JONHSON, H.B. Plant pubescence: an ecological perspective. Botanical Review, Chicago, v.41, p.233-258, 1975.

KASPERBAUER, M.J.; HAMILTON, J.L. Chloroplast structure and starch grain accumulation in leaves that received different red and far-red levels during development. Plant Physiology, Washington, v.74, p.967-970, 1984.

KENDRICK, R.E.; KERCKHOFFS, L.H.J.; TUINEN, A. van; KORNNEEF, M. Photomorphogenic mutants of tomato. Plant Cell and Environment, v.20, p.746-751, 1997.

KERCKHOFFS, L.H.; GROOT, N.A.M.A.; TUINEN, A. van; SCHREUDER, M.E.L.; NAGATANI, A.; KORNNEEF, M.; KENDRICK, R.E. Physiological characterization of exaggerated-photoresponse mutants of tomato. Journal of Plant Physiology, Bethesda, v.150, p.578-587, 1997.

KIM, G.T.; YANO, S.; KOZUKA, T.; TSUKAYA, K. Photomorphogenesis of leaves: shade-avoidance and differentiation as sun and shade leaves. Photochemistry Photobiology Science, v.4, p.770-774, 2005.

KOZUKA, T.; HORIGUCHI, G.; KIM, G.T.; OHGISHI, M.; SAKAI, T.; TSUKAYA, H. The different growth responses of the Arabidopsis thaliana leaf blade and the petiole during shade avoidance are regulated by photoreceptors and sugar. Plant Cell Physiology, v.46, p.213-223, 2005.
KRAUS, J.E.; ARDUIM, M. Manual básico de métodos em morfologia vegetal. Seropédica: EDUR, 1997. 198p.

LABOURIAU, L.G.; OLIVEIRA, J.G.; SALGADOLABOURIAU, M.L. Transpiração de Schizolobium parahyba (Vell) Toledo I: comportamento na estação chuvosa, nas condições de Caeté, Minas Gerais. Anais da Academia Brasileira de Ciências, Rio de Janeiro, v.23, p.237-257, 1961.

LIMA JUNIOR, E.C.; ALVARENGA, A.A.; CASTRO, E.M.; VIEIRA, C.V.; BARBOSA, J.P.R.A.D. Aspectos fisioanatômicos de plantas jovens de Cupania vernalis Camb. submetidas a diferentes níveis de sombreamento. Revista Árvore, Viçosa, v.30, p.33-41, 2006.

LIU, Y.; ROOF, S.; ZHIBIAO, Y.; BARRY, C.; TUINEN, A. van; VREBALOV, J.; BOWLER, C.; GIOVANNONI, J. Manipulation of light signal tranduction as a means of modifying fruit nutritional quality in tomato. PNAS Plant Biology, 2004. Disponível em: <http:// iwww.pnas.org/misc/rightperm.shtmly. Acesso em: 13 nov. 2006.

MARTÍ, E.; GISBERT, C.; BISHOP, G.J.; DIXON, M.S. Genetic and physiological characterization of tomato cv. Micro-Tom. Journal of Experimental Botany, Madison, v.57, p.2037-2047, 2006.

MELO, H. C.; CASTRO, E. M.; SOARES, A. M.; OLIVEIRA, C.; RAMOS, S. J. Características fisiológicas de microtomateiros fitocromo-mutantes. Ciência e Agrotecnologia, v.33, p. 1213-1219, 2009.

MEISSNER, R.; JACOBSON, Y.; MELAMED, S.; LEVYATUV, S.; SHALEY, G.; ASHRI, A.; ELKIND, Y.; LEVY, A. A new model systema for tomato genetics. Plant Journal, Shannon, v.12, p.1465-1472, 1997.

NAGATANI, A.; REED, J.W.; CHORY, J. Isolation and initial characterization of Arabidopsis mutants that are deficient in phytochrome A. Plant Physiology, Washington, v.102, p.269-277, 1993.

NAKAZONO, E.M.; COSTA, M.C.; FUTATSUGI, K.; PAULILO, M.T.S. Crescimento inicial de Euterpe edulis Mart. em diferentes regimes de luz. Revista Brasileira de Botânica, São Paulo, v.24, p.173-179, 2001. 
NASCIMENTO, E.A.L.; PLIVEIRA, L.E.M.; CASTRO, E.M.; DELÚ FILHO, N.; MESQUITA, A.C.; VIEIRA, C.V. Alterações morfofisiológicas em folhas de cafeeiro (Coffea arabica L.) consorciado com seringueira (Hevea brasiliensis Muell. Arg.). Ciência Rural, Santa Maria, v.36, p.852-857, 2005.

PETERS, J.L.; SZELL, M.; KENRICK, R.E. The expression of light-regulated genes in the high-pigment1 mutant of tomato. Plant Physiology, Washington, v.117, p.797-807, 1998.

PRATT, L.H.; CORDONNIER-PRATT, M.M.; KELMENSON, P.M.; LAZAROVA, G.I.; KUBOTA, T.; ALBA, R.M. The phytochrome gene family in tomato (Solanum lycopersicon L.). Plant Cell and Environment, v.20, p.672-677, 1997.

\section{SCHITTENHELM, S.; MENGE-HARTMANN, U.;} OLDENBURG, E. Photosynthesis, carbohydrate metabolism, and yield of Phytochrome-B-Overexpressing potatoes under different light regimes. Crop Science, Madison, v.44, p.131-143, 2004.

SHARMA, R.; LÓPEZ-JUEZ, E.; NAGATANI, A.; FURUYA, M. Identification of photo-inactive phytochrome A in etiolated seedlings and photoactive phytochrome B in green leaves of aurea mutant of tomato. Plant Journal, Shannon, v.4, p.1035-1042, 1993.

SMITH, H. Physiological and ecological function within the phytochrome family. Annual Review Plant
Physiology Plant Molecular Biology, Palo Alto, v.46, p.289-315, 1995.

TERASHIMA, I.; MIYAZAWA, S.I.; HANBA, Y.T. Why are sun leaves thicker than shade leaves?: consideration based on analyses of $\mathrm{CO}_{2}$ diffusion in the leaf. Journal Plant Reearch, v.114, p.93-105, 2001.

TERASHIMA, I.; SAKAGUCHI, S.; HARA, N. Intra-leaf and intracellular gradients in chloroplast ultrastructure of dorsiventral leaves illuminated from the adaxial or abaxial side during their development. Plant Cell Physiology, v.27, p.1023-1031, 1986.

TERRY, M.J.; KENDRICK, R.E. The aurea and yellowgreen-2 mutants of tomato are deficient in phytochrome chromophore synthesis. The Journal of Biological Chemistry, v.271, p.21681-21686, 1996.

TERRY, M.J.; KENDRICK, R.E. Feedback inhibition of chlorophyll synthesis in the phytochrome chromophore-defidient aurea and yellow-green-2 mutants of tomato. Plant Physiology, Washington, v.119, p.143-152, 1999.

TSUKAYA, H.; KOZUKA, T.; KIM, G.T. Genetic control of petiole length in Arabidopsis thaliana. Plant Cell Physiology, v.43, p.1221-1228, 2002.

WERKER, E. Trichome diversity and development. In: HALLAHAN, D.L.; GRAY, J.C. Plant trichomes. London: Academic, 2000. p.1-30. 